\title{
Real Convergence in the New Member States: Myth or Reality?
}

\author{
Andrea Ingianni \\ Kingston University \\ Václav Žd'árek \\ University of Economics in Prague
}

\begin{abstract}
The paper analyses the process of real convergence of the New Member States of the European Union. Its importance is underlined in connection with a successful catching-up and a special attention is paid to the countries involved in the fifth European enlargement, with the exception of Cyprus and Malta. We note that, over the last decade, these economies experienced robust economic growth, which had a stronger impact on the convergence process within the EU8 group than to EU15. Our assumptions are investigated empirically by a comparison of beta and sigma-convergence analysis with time-series based stationarity and cointegration tests.
\end{abstract}

- JEL Classification : C22, F02, O52, O11

- Key Words: real convergence, EU enlargement, time series

\footnotetext{
*Corresponding address: Andrea Ingianni: School of Economics, Kingston University, Penhryn Road, Kingston Upon-Thames, Surrey, KT1 2EE, England. Tel: +44 (0) 208417 2370. e-mail: a.ingianni@kingston.ac.uk, Václav Žd'árek: Centre for Economic Studies, University of Economics and Management, University of Economics in Prague, I. P. Pavlova 3 Chech Repulice, CZ-120 00 Prague 2 Chech Repulice, e-mail: vaclav.zdarek@vsem.cz, Department of Monetary Theory and Policy, W. Churchill Sq. 4, CZ-130 67, Prague 3, Chech Republic, Tel: +42 (0) 22409 5640. e-mail: zdarekv@vse.cz. ( $2009-$ Center for International Economics, Sejong Institution, Sejong University, All Rights Reserved.
} 


\section{Introduction}

The fifth and sixth ${ }^{1}$ enlargements of the European Union (EU) - in 2004 and 2007 - are still relatively recent. Nevertheless, many of the new EU states are currently in a situation where a plan for introducing the single currency is in place and a preliminary date for joining the Euro area has been set. A decision on whether or not to join will be required in a few years time. ${ }^{2}$ In this context, it is interesting to consider whether the membership of the EU and in particular of the Euro area, will produce a certain level of convergence among the new member states. $^{3}$ An analysis of the development of nominal and real convergence including a comparison of the economies involved in the process is therefore highly relevant and necessary.

Several new approaches to explaining the phenomena observed in reality have been presented over the last two decades. Modern concepts of the endogenous growth theory have been developed to reflect a range of previously neglected factors, such as education, institutional quality, etc. Due to these dissimilarities, one permanent steady state cannot exist in otherwise identical economies. In particular, these models can be used to explain theoretically the development of faster growing economies when a broad gap in economic levels is observed empirically.

Some countries grow faster than others in spite of achieving a higher output, while others may continue to lag behind. There have been a number of studies examining real convergence in both developed and developing countries. In particular, we identify three main strands in the recent literature focusing on real convergence in Central and Eastern European economies.

The first strand works with long-term GDP series employing either standard measures of sigma and beta convergence - e.g. Matkowski and Próchniak (2007a) - or the time-series approach - e.g. Christopoulos and Leon-Ledesma (2007) or Bruggemann and Trenkler (2007). ${ }^{4}$ Such studies utilise data for the post-war period

\footnotetext{
${ }^{1}$ Estonia, Lithuania, Latvia, Czech Republic, Slovakia, Hungary, Poland, Slovenia, Malta, Cyprus (5th) and Romania, Bulgaria (6th).

${ }^{2}$ In our paper we discuss eight new EU member states (EU8) excluding the Mediterranean countries. Cyprus and Malta are somewhat different both in terms of economic indicators (structural characteristic of their economies) and past political experiences. The newcomers Bulgaria and Romania are not included into our analysis due to datasets problems.

${ }^{3}$ Slovenia has already adopted the common currency and it is the $13^{\text {th }}$ member of the Euro area (twelve member states prior to 2007). Cyprus and Malta joined in 2008 and Slovakia adopted the Euro in January 2009 ( $16^{\text {th }}$ member).

${ }^{4}$ Other studies focus on real convergence understood as changes of total factor productivity; see e.g. Kutan and Yigit (2007).
} 
or longer. ${ }^{5}$

The second stream takes a broader prospective conditioning convergence to several economic indicators - such as industrial production in Kutan and Yigit (2004) or Kocenda (2001) - and usually employs time series analysis. ${ }^{6}$

The third group of studies specifically looks at eastern European countries in the post-liberalization period. Dobrinsky (2003) and Matkowski and Prochniak (2004) focus on the new member states of the European Union while Kocenda et al. (2006) on the EU8 against the core or periphery of the EU. A comprehensive review is available in Kocenda et al. (2006) or Matkowski and Próchniak (2007a).

\section{A. What Do We Know about Convergence in the EU8?}

The conclusions reached by different authors within the three groups identified above are mixed. Matkowski and Prochniak (2004) found a relatively fast convergence process in the EU8 countries during the period 1993-2004 and for the sub-periods 1993-1998 and 1998-2004 with a speed of convergence varying within the narrow band $1.7 \%-2.7 \%$. For the EU8 and EU15 regions, the band is found to be even narrower at $2.2 \%-2.5 \%$. A potential problem may be the inclusion of the early years of the transition (1993-1994) which may bias the results mentioned above, in particular reducing the speed of convergence.

Kocenda et al. (2006) focused on real and nominal convergence in EU8 in relation to the average GDP per capita in the core (Austria, Belgium, France, Germany and the Netherlands) and periphery of EU (Greece, Portugal and Spain). They used quarterly GDP both in national currency and in Euros (1996-2005). The best performance in terms of speed of convergence is associated with the Baltic States which however does not appear strong enough to shrink the GDP gap in Euro terms.

Kutan and Yigit (2004) tested real and monetary stochastic convergence for selected transition countries over the period 1993-2000. They used industrial production (monthly time series) as a proxy of real convergence in order to capture both potential supply and demand shocks. These authors make reference to EU5 and the Baltic States, EU6 countries and Bulgaria and Romania. Their findings confirmed the existence of real convergence in/with the EU6 and the Baltic States. Our research differs in the choice of target countries, sample size and time-series

\footnotetext{
${ }^{5}$ This type of analysis is subject to a large number of problems due to estimates of GDP prior to the First World War; for a discussion see e.g. IMF (2007).

${ }^{6}$ Some authors also focus on nominal convergence in the light of the Euro adoption.
} 
tests for convergence.

Kocenda (2001) has a very similar approach including real and nominal convergence, industrial production and monthly time series covering the period 1991-1998. The conclusion is in favour of a strong decline in output during the first part of the sample and then surprisingly high growth rates in the second. We suspect this behaviour to be biased by the inclusion of the beginning of the transformation process (early 90s).

Dobrinsky (2003) studied real and nominal convergence and the linkages between them. Real convergence is measured in GDP per capita (PPP) with the help of growth accounting (Solow residual), for the period 1990-2003. The major conclusion of the paper is that the robust real convergence in CEE and CIS countries is supported by strong growth in total factor productivity.

Finally, Christopoulos and Leon-Ledesma (2007) or Bruggemann and Trenkler (2007) both use a time series methodology which is quite close to ours ${ }^{7}$ and we reserve to discuss them more in depth in Section IV.

\section{B. Organisation of the Paper}

The contributions of this article in respect to existing research are several.

Firstly we use a larger sample than the majority of existing research focusing on the post liberalization period and we develop a simple panel specification to increase the reliability of the beta convergence estimate.

Secondly, we use data sets expressed either in PPS or 2000 constant prices. Common PPP alternatives suffer from bias due to prices calculated from large and heterogeneous groups of poor countries. 2000 constant prices are superior to 1995 constant prices mainly because of methodological changes initiated by Eurostat.

Finally, we use time-series analysis to look at the long run perspective. Here we implement a non linear alternative to commonly used unit-root tests and consider smooth structural changes and asymmetric adjustments. We also discuss the role of the latter in small samples.

In general, the process of real convergence is an important issue and the authors' impression is it needs a strong research effort, especially since there are many methodological and empirical problems connected with growth analysis in general and the new EU member states in particular. However, it is likely that significant changes cannot be expected within just a few years. The economic output of the

$\overline{{ }^{7} \text { Christopoulos and Leon-Ledesma (2007) however is not specifically oriented to the EU8. }}$ 
EU8 will continue to grow in the near future but possibly at a slower pace when the new member states will eventually approach the average level of the European Union. Meanwhile they are likely to grow at a higher rate than the EU average in order to reduce their gap vis-à-vis the old member states and this process can be accompanied by fundamental structural changes with important economic implications.

The rest of the paper tries to find some empirical support to these predictions and it is organised as follows. Section II discusses the dataset used in the empirical analysis. In Section III we deal with the estimation of $\beta$ and $\sigma$-convergence in a simple panel data setting. Section $\mathrm{V}$ approaches convergence in the time-series prospective using unit root tests and cointegration. The last section summarises our main results and concludes.

\section{Data}

The questionable quality of the data for transition countries is, in general, well known. The problem is even bigger when considering the former centrally planned economies of Central and Eastern Europe. Redrawing national borders in this part of the continent after the start of economic and political transformation, has aggravated this kind of problems. The few available estimates for former centrally planned economies can form the basis for longer-term comparative studies - see UNECE (2000). However, their analytical power with respect to the analysis of current events is limited by both the changes in national borders and the methodological deficiencies in the data. For this reason, comparisons are very problematic. $^{8}$

Transition countries, as opposed to developed economies, have undergone a radical economic change from a centrally planned to a market-based economy which was accompanied by a large decline of output throughout the region. Some studies show that the economic decline (measured in real GDP), which is usually associated with this period, may have been overestimated. ${ }^{9}$

Another significant problem is expressing GDP in the appropriate currency. Where possible, we adjust for purchasing power parity and distinguish between the PPS unit and PPP of the currency (for example the US dollar) published by the

${ }^{8}$ For additional explanations and estimates of long-term developments, see e.g. Dobrinsky et al. (2006). ${ }^{9}$ See for example, Dobozi and Pohl (1995). 
OECD (the USA are the country of reference) or the World Bank. The purchasing power standard (PPS) is an artificial unit created by Eurostat according to the average price level across the EU states. The best solution would be to calculate GDP growth rates in constant PPS but this data are not published by Eurostat.

Furthermore, the only data easily accessible are in annual frequencies, which we do not judge adequate for the time-series techniques described later in Section V.

In these circumstances we used quarterly per capita GDP in Euros both for individual new EU Member states and for the EU15 aggregate (chain-linked 2000 constant prices) ${ }^{10}$. Population growth rates are based on the Annex of ECFIN (2006) and Eurostat New Cronos database. Our data covers the 12 years period 1995-2006. The aggregation methodology follows internal Eurostat procedures, with the exception of the EU8 average which we constructed as weighted average of the country's GDP in Euro valued at PPS due to the non-existence of official figures. Weights are calculated dividing individual countries' GDP in PPS by the total EU8 GDP in PPS.

\section{Convergence by Catching-up}

\section{A. Beta Convergence}

With reference to the neoclassical Solow (1956) or Cass (1965) growth models and in the context of absolute convergence, beta convergence is understood as a long run phenomenon in the course of which poor economies tend to grow at higher rate than rich ones. For a single or an aggregated set of countries the idea of beta convergence can be expressed in the form of (1) and requires $\beta<0$ :

$$
T^{-1} \ln \left(\frac{y_{T}}{y_{0}}\right)=\alpha+\beta \ln \left(y_{0}\right)
$$

where the left hand side of equation (1) shows the average growth of log output between the period $t=0$ and $t=T$. If we call $\beta_{\mathrm{s}}$ the speed of convergence towards the steady state (i.e. the gap reduction against the steady state of a given economy during one year):

\footnotetext{
${ }^{10}$ We used 2000 constant prices, even though we are conscious of the potential bias generated by the use of onstant prices in transition countries. This is also the reason why we did not use GDP per capita 1995 current prices. The best choice would have been the chain-linked time series with prices of the previous year, which however are not available for most of the EU8 countries. For a discussion of price bias in case of transition countries, see e.g. Filer and Hanousek (2004).
} 


$$
\beta_{s}=\frac{1-e^{-\beta T}}{T}
$$

For example, supposing the parameter $\beta_{\mathrm{s}}$ is equal to 2.5 , the economy in question will surpasses $2.5 \%$ of the distance between the actual and steady state every year. Using OLS, we estimate a simple panel approximation of equation (1) derived from Young et al. (2007), with reference to a group of countries $i=1,2, \ldots, N$ sharing the same steady state - i.e.

$$
T^{-1} \ln \left(\frac{y_{T, i}}{y_{0, i}}\right)=\alpha+\beta \ln \left(y_{0, i}\right)+\varepsilon_{[0, T], i} \text { and } \varepsilon_{[0, T], i} \sim N\left(0, \sigma_{\varepsilon}^{2}\right) .
$$

Our target is only to slightly improve the quality of the statistics given the small sample size; any disaggregated analysis is performed using time-series in section V.

The results are shown in Table 1 (GDP expressed in Euros) and Figure 1 illustrates. GDP per capita series for all the EU8 are plotted in the Appendix - see Figure A1.

Table 1 shows that the rate of convergence was relatively low for GDP per capita in Euros but in line with other studies. ${ }^{11}$ This is probably caused by the unit of account: the process of real convergence is affected not only by differences in output (increase of value added and structural changes), but also by the appreciation of domestic currencies. ${ }^{12}$

Another indicator often used to measure beta convergence is GDP per capita in

Figure 1. Growth and Initial log GDP p.c.
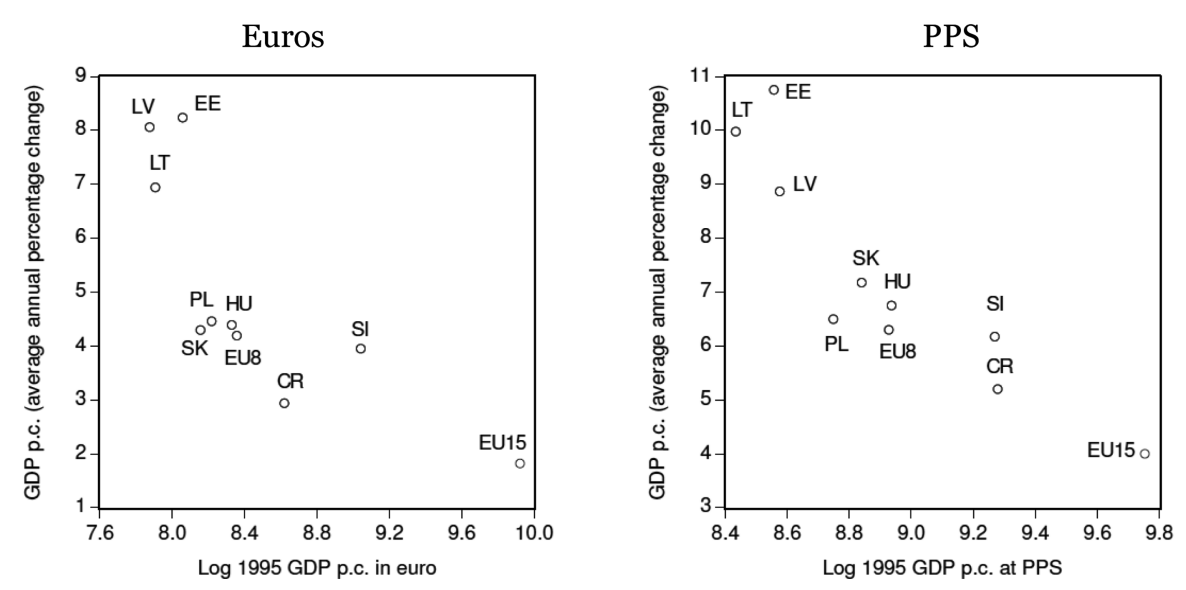
Table 1. Beta Convergence

\begin{tabular}{cccccc}
\hline & $\alpha$ & $\beta$ & Adj. $R^{2}$ & $\beta_{s}$ & Conv. \\
\hline EU8 (eur) & 0.1825 & -0.0158 & 14.13 & $1.74 \%$ & yes \\
$1995-2006$ & $(0.0510)$ & $(0.0059)$ & & & \\
EU23 (eur) & 0.0834 & -0.0089 & 54.53 & $0.94 \%$ & yes \\
$1995-2006$ & $(0.0032)$ & $(0.006)$ & & & \\
EU8 (pps) & 0.5704 & -0.0542 & 37.49 & $7.63 \%$ & yes \\
$1995-2006$ & $(0.0895)$ & $(0.0097)$ & & & yes \\
EU23 (pps) & 0.1090 & -0.0094 & 44.5 & $1.00 \%$ & \\
$1995-2006$ & $(0.0046)$ & $(0.0078)$ & & & \\
\hline
\end{tabular}

Notes: Observations: $88(N=8, T=11)$ or $253(N=23, T=11)$, own calcualtions. S.E. In parentheses.

PPS for which we obtain dissimilar results (see Table 1). The relatively high speed of convergence is influenced by the fact that the indicator is expressed in terms of current PPS. This is de facto equivalent to prices of the current year, incorporating changes in price structures and in the composition and terms of trade. According to our results, it will still take more than a few decades to reduce the gap between the most successful EU8 countries and the the EU15 income levels.

Table 1 also shows an estimate of the convergence process between EU8 countries and EU15 countries inside EU23 (two regions - a simple analogy to the core periphery approach). Our estimates of the speed of convergence are quite low, compared to Matkowski and Próchniak (2007a) (approximately one half times). It is however difficult to compare the results due to the different sample size (1993-2004), estimation strategy (standard OLS) and values at PPP of Matkowski and Próchniak (2007a). Finally we note how the same authors estimate beta convergence in two separate sub-samples, de facto assuming a structural break in 1998. Rather than fixing it a priori, we prefer to consider it endogenous and eventually estimate it from the data. We approach the problem formally in Section V.

\section{B. Sigma Convergence}

Since the first part of our analysis corroborated the existence of betaconvergence among EU8 countries, another interesting question seems to be whether the income dispersion among these countries has also diminished. This question can be answered with the help of sigma convergence. If the less

\footnotetext{
${ }^{11}$ The speed of convergence is considerably reduced when compared to standard OLS estimations-see Matkowski and Prochniak (2007a).

${ }^{12}$ The indicator valued at Euros takes into account not only the real development (changes in constant prices), but also the appreciation of domestic currencies against the Euro.
} 
developed countries among EU8 tend to grow at higher rates (e.g. the Baltic States) than the more developed (e.g. the countries of the Visegrad group), the intuitive implication is that income dispersion among these countries needs to decline over time. As a rough and preliminary measure of this behaviour, we test the existence of a significant linear trend in the standard deviation of log GDP per capita - i.e.

$$
\sigma_{t}^{2}=\alpha+\beta t+\varepsilon_{t}, \beta<0
$$

More generally, when the variance tends to decline over time, a group of countries (e.g. EU8 or EU23) sigma-converge. Formally:

$$
\sigma_{t+n}^{2}<\sigma_{t}^{2}
$$

where $n>0, t=1,2, \ldots \ldots, T, n=1,2, \ldots \ldots . N$ number of countries in the aggregate. $\sigma_{t}^{2}$ is the variance of $\log$ GDP for the aggregate at time $t$, calculated as: $\sigma_{t}^{2}=N^{-1} \sum_{i=1}^{N}\left[\ln \left(y_{i, t}\right)-\bar{y}_{t}\right]^{2}$ and $\bar{y}_{t}=N^{-1} \sum_{i=1}^{N} \ln \left(y_{t, i}\right)$.

We used GDP per capita in Euros and our results for the first approach are summarized in Table 2.

We note that, in contrast to our results for beta convergence, the simple specification adopted to model sigma-convergence, is possibly insufficient for reliable conclusions in the sample under investigation. In this context, we propose Table 2 and Figure 2 as exploratory investigation of a behaviour that will be more formally investigated later in the paper. This informal evidence suggests the possibility of sigma-convergence within the EU8 group. Income dispersion among EU8 countries was decreasing over the full period, with the only exception of a

\begin{tabular}{|c|c|c|c|c|}
\hline & $\alpha$ & $\beta$ & $R^{2}$ & $\sigma$-convergence \\
\hline EU23 (eur) & 0.3654 & 0.0003 & \multirow{2}{*}{7.53} & \multirow[b]{2}{*}{ no } \\
\hline 1995-2006 & $(0.0021)$ & $(0.0003)$ & & \\
\hline EU8 (eur) & 0.4018 & -0.0103 & \multirow{2}{*}{96.37} & \multirow{2}{*}{ yes } \\
\hline 1995-2006 & $(0.0047)$ & $(0.0006)$ & & \\
\hline $\begin{array}{l}\text { EU23 (pps) } \\
1995-2006\end{array}$ & $\begin{array}{c}0.2329 \\
(0.0059)\end{array}$ & $\begin{array}{c}0.0024 \\
(0.0008)\end{array}$ & 48.08 & no \\
\hline $\begin{array}{c}\text { EU8 (pps) } \\
1995-2006\end{array}$ & $\begin{array}{c}0.3267 \\
(0.0045)\end{array}$ & $\begin{array}{l}-0.0125 \\
(0.0006)\end{array}$ & 97.71 & yes \\
\hline
\end{tabular}

Table 2. Sigma Convergence 
Figure 2. Standard Deviation in the EU8 and EU23
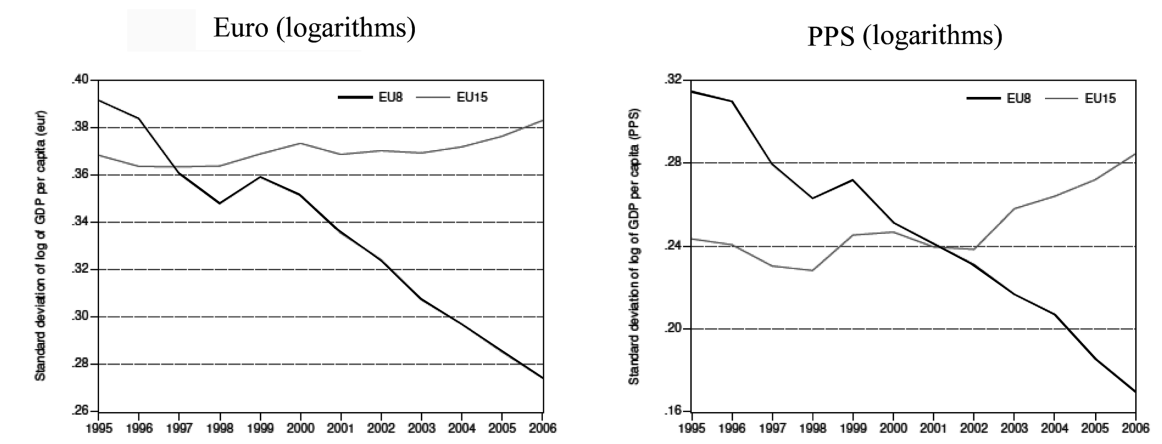

few years at the end of the 90s. These results are compatible with Matkowski and Próchniak (2007b) who confirmed the existence of both types of convergence in the EU8 countries using different data sources (Groningen Database, UNECE Database or IMF Database with GDP in PPP USD). Figure 2 and Table 2 also show how, within the enlarged EU23 group, the same conclusion does not apply. Here we note some degree of divergence which we will investigate on an individual countries basis in the next section. The second part of our analysis is based on GDP per capita at PPS and confirms the results already discussed for the series expressed in Euros. Additionally, we note that in the case of EU8, the positive conclusion for convergence can not be reached if the GDP per capita series are not linearised.

\section{Comparison}

Sections III.A and III.B show that the EU8 countries have experienced some convergence in terms of both beta and sigma measures. It is well known that beta convergence is a necessary but not sufficient condition for sigma convergence see i.e. Young et al. (2007). This fact is clearly reflected in our regressions, where beta- and sigma-convergence both hold for EU8 but the second is not confirmed in EU23. This is not entirely surprising considering that the EU23 consists of a set of countries at different stages of economic development with different levels of per capita income. The more disparate range of external shocks experienced by the larger group of countries may produce sigma-divergence even when there is sufficient catching-up between EU8 and EU15 to support the evidence of betaconvergence.

A discussion of this possibility alongside the role of PPP vs. PPS and 
aggregation issues can be found in Bonn et al. (2006) while Matkowski and Próchniak (2007a) consider the same topic for different time periods.

\section{The Time-series Approach}

With the aim of addressing the well known Quah (1993) and Bernard and Durlaf (1995), Bernard and Durlauf (1996) criticism to the Barro and Sala-Martin (1992) framework, in this section we attempt to analyse the convergence hypothesis under the time series perspective. For this purpose and in the hope of improving the significance of our statistics, we increase the data frequency to quarterly observations making reference to Eurostat GDP, million of Euros, at fixed 2000 prices and exchange rates. Equivalent series in PPS are not available from Eurostat. We maintain the 1995-2006 sample for a total of 48 observations. The per capita series are derived assuming equal weights for every quarter in the same year for the population series and seasonal components are removed before testing. Linear and non-linear alternatives are considered in sections IV.A and IV.B respectively.

\section{A. Linear Stochastic Convergence}

A way of defining convergence proposed by Carlino and Mills (1993) is examining the presence of a unit root in the log per capita income of one country relative to that of a second reference country or an economic area as a whole. We refer to this notion as time-series convergence. Bernard and Durlauf (1995), Bernard and Durlauf (1996) also proposed definitions of convergence from longrun forecasts.

For example, for each country $i$, the logarithm of the ratio of per capita income relative to the average of all countries in the same area can be defined as:

$$
G_{i, t}=\ln \left(\frac{y_{i, t}}{N^{-1} \sum_{j=1}^{N} y_{i, t}}\right), i=1,2, \ldots, N
$$

where $y_{i, t}$ is the per capita income for country $i$ and $N$ is the number of countries of interest. A failure to reject the null hypothesis of a unit root in $G_{i, t}$ indicates evidence against income convergence. In this case, following a shock to relative income in country $i$ there is no tendency for per capita income to return to the average; thus implying that income diverges over time. On the contrary, the rejection of a unit root supports the alternative hypothesis that shocks to relative income are temporary, implying that incomes converge. 
Generalizing equation (4), GDP per capita in country $i$ diverges from country $j$ when the difference:

$$
g_{t}=\ln \left(y_{i, t}\right)-(\ln )\left(y_{j, t}\right)
$$

is non stationary or has zero mean.

If the concept of stationarity is seen under the unit root perspective, the problem can be summarized as follows. When the process $g_{t}=\rho g_{t-1}+\varepsilon_{t}$ which is equivalent to $(\rho-1=\alpha)$ :

$$
\Delta g_{t}=\alpha g_{t-1}+\varepsilon_{t}
$$

has a unit $\operatorname{root}(\rho=1, \alpha=0)$ it is a non-stationary random walk and it should be interpreted in the sense of output divergence between two selected countries $i$ and $j$. A unit root can be either pure or stochastic with different implications in terms of convergence (see section IV.B).

We start our application by testing the existence of a pure unit root using the standard Dickey and Fuller (1979) test with three alternative specifications: a simple model as in (6) and two alternative models with a constant and a trend.

$$
\begin{gathered}
\Delta g_{t}=\alpha g_{t-1}+\gamma+\sum_{q=1}^{Q} \beta_{q} \Delta g_{t-q}+\varepsilon_{t} \\
\Delta g_{t}=\alpha g_{t-1}+\gamma+\delta t+\Sigma_{q=1}^{Q} \beta_{q} \Delta g_{t-q}+\varepsilon_{t}
\end{gathered}
$$

with selected lag-length (in the example).

Overall our results seem to suggest a weak evidence of convergence in the Carlino and Mills (1993) sense (stationary difference series with zero mean). However, the estimation of the coefficients in the test equations is affected by a variety of factors, different from country to country. These range from insignificant coefficients and poor fit to some degree of serial correlation in the disturbances. Augmenting the specification for an appropriate number of lags helps in some cases. In others, residual seasonal components influence the quality of the analysis.

Among the three specification used, we indicated the most reliable in statistical terms. Clearly, the definition of convergence varies according to the specification used (i.e. level or trend stationarity). The general conclusion against it however, makes the distinction irrelevant in this particular example. We also note the 
Table 3. Stationary Tests (with EU15)

\begin{tabular}{ccccccccc}
\hline None & $\mathrm{lt}$ & $\mathrm{lv}$ & $\mathrm{ee}$ & $\mathrm{cz}$ & $\mathrm{sk}$ & $\mathrm{pl}$ & $\mathrm{hu}$ & $\mathrm{sl}$ \\
\hline$t$-stat & -3.28 & -6.60 & -3.93 & -1.50 & -2.59 & -2.53 & -3.49 & -4.09 \\
stationary? & yes & yes & yes & no & yes & no & yes & yes \\
\hline Constant & $\mathrm{lt}$ & $\mathrm{lv}^{*}$ & $\mathrm{ee}$ & $\mathrm{cz}^{*}$ & $\mathrm{sk}$ & $\mathrm{pl}$ & $\mathrm{hu}$ & $\mathrm{sl}$ \\
\hline$t$-stat & 0.06 & 2.34 & 0.25 & 0.79 & 0.85 & -1.31 & 0.82 & -0.17 \\
stationary? & no & no & no & no & no & no & no & no \\
\hline Const. + trend & $\mathrm{lt}^{* *}$ & $\mathrm{lv}$ & $\mathrm{ee}^{* *}$ & $\mathrm{cz}$ & $\mathrm{sk}^{*}$ & $\mathrm{pl}^{* * *}$ & $\mathrm{hu}^{* *}$ & $\mathrm{sl}^{* *}$ \\
\hline$t$-stat & -1.88 & -0.33 & -2.22 & -0.58 & -0.29 & -4.45 & -4.17 & -2.77 \\
stationary? & no & no & no & no & no & yes & yes & no \\
\hline
\end{tabular}

Source: Eurostat (2007) National Accounts ( $\mathrm{T}=48)$, own calcualtions. Note: critical values in Dickey and Fuller (1979).

empirical results at this stage are quite far from our beta-convergence estimates in Section III.A. This is not totally unexpected, given the theoretical difference between the two approaches. Carlino and Mills (1993) see them as two separate conditions for convergence. If we can prove the first ${ }^{13}$, we still struggle on the second.

In search of a more reliable time-series test for the convergence hypothesis, we follow Bernard and Durlaf (1995) and Daly and Li (2005) with elements from Johansen (1995) and use the concept of cointegration looking for the number of stationary linear combinations generated by two individually I(1) series. When a unique relation is identified between two countries, we conclude for convergence. Bruggemann and Trenkler (2004) used a similar procedure with some differences.

Similarly, they expressed the Bernard and Durlaf (1995) definition in terms of the properties of the cointegrating vector and used Johansen (1991) to test for it. However, they restricted the analysis to three accession countries and focused on industrial production rather than GDP per capita. Germany is used as a proxy for EU15, instead of an average/aggregate series. In a later paper, Bruggemann and Trenkler (2007) shift the research objective to GDP per capita and catching up. Instead of using recursive cointegration tests based on Johansen (1991), they rely on Lee and Strazicich (2003). We start from the first methodology which we apply to GDP per capita series of all EU8 countries.

The Johansen (1991) cointegration test is used as follows. Consider the (unrestricted) VAR process of order $p$, expressed in differences as:

\footnotetext{
${ }^{13}$ See Section III.A.
} 


$$
\Delta y_{t}=\Pi y_{t-1}+\sum_{i=1}^{p-1} \Delta y_{t-i}+B x_{t}+\varepsilon_{t}
$$

where $A_{j}$ is the generic coefficient of the lagged variable $y_{t-j}$ used for computing $\Gamma_{i}=\sum_{j=i+1}^{p} A_{j}$ and $\Pi=\sum_{i=1}^{p} A_{i}-I$. Additionally, $y_{(l, k)}$ is a vector of level non stationary series such as $y_{(1, k)}=\left[y_{1}, y_{2}, \ldots, y_{d}\right]$ and $y_{1} \sim \ldots \sim y_{d} \sim I(1)$, $x_{(1, d)}=\left[x_{1}, x_{2}, \ldots, x_{d}\right]$ is a vector of deterministic components (regressors) and $\varepsilon_{\mathrm{t}}$ the innovation (disturbances) vector. In our empirical exercise, $\mathrm{y}_{(1, k)}$ represents the vector of the log GDP per capita of the economies under investigation (individual EU8 or EU15).

According to the Engle and Granger (1987)'s representation theorem, if the matrix $\Pi$ has reduced rank $(\tau<k)$, then there must exist an $\alpha$ and $\beta$ of dimensions $(k \times \tau)$ such as their rank is equal to $\tau$, the product $\alpha \beta^{\prime}=\Pi$ and, most importantly in our perspective, $\beta^{\prime} y_{t} \sim I(0)$. Formally:

$$
r(\Pi)=r<k \Rightarrow \exists \alpha_{(k \times \tau)}, \beta_{(k \times \tau)} \mid r(\alpha)=r(\beta)=\tau \wedge \Pi=\alpha \beta^{\prime} \wedge \beta^{\prime} y_{t} \sim I(0)
$$

In the Johansen (1991) formulation, $\beta$ is the matrix of cointegrating vectors, $\alpha$ the adjustment factors, and $\tau$ the number of cointegrating relations.

To find the $r(\Pi)=\tau$ (the number of cointegrating relations), first Johansen (1991) imposes the appropriate assumptions on the trend. In the specific case we are interested in no trend or intercept to match the definition of convergence we proposed in previous sections:

$$
\Pi y_{t-1}+B x_{t}=\alpha \beta^{\prime} y_{t-1} .
$$

If we assume no additional exogenous variables $\left(B x_{t}=0, \forall t\right)$, we can simply write:

$$
\Pi y_{t-1}=\alpha \beta^{\prime} y_{t-1} .
$$

Afterwards, we can use sequentially the Johansen (1991) trace statistic, ${ }^{14}$ in the range of $t=0,1, \ldots . ., k-1$, trying for every step to reject the null $\left(\mathrm{H}_{0}\right)$ :

$$
\mathrm{H}_{0}: r(\Pi)=\tau, \quad \mathrm{H}_{1}: r(\Pi)=k
$$

$\left(\mathrm{H}_{0}: \Pi\right.$ has reduced rank, $\mathrm{H}_{1}: \Pi$ has full rank) until failure. Critical values are non standard and have been obtained through Montecarlo simulations by Osterwald-

\footnotetext{
$\overline{{ }^{14} \text { See op. cit. for a full discussion. }}$
} 
Lenum (1992). Since we are using the cointegration test mainly as an alternative to the ADF, it is worth noting that a condition of conflicting results with individual unit roots is usually to be attributed either to low power or misspecification. The first is more frequent in presence of small sample sizes. Johansen (2002) introduced a correction factor for these particular cases.

We apply the test pairwise to the log of individual EU8 and EU15 GDP per capita we reach the results summarized in Table 4 . Now we seem able to confirm the convergence hypothesis, although a number of limitations make the tests not very powerful. We find quite strong (1 percent significance) evidence of one cointegrating relation between the majority of series concluding for a unique trend in the long run.

This conclusion, paired with the beta-convergence evidence from Section III.A adds some preliminary support in favour of stochastic convergence in the Carlino and Mills (1993) sense for the EU enlargement case.

\section{B. Non-linear Stochastic Convergence}

At least three considerations motivate us to abandon the linear specification we used in various forms in Section IV.A. Firstly, the linear ADF tests posed several difficulties and demonstrated to have poor performance in our particular case. Other than the problems already mentioned in Section IV.A, the feeling is a linear

Table 4. Cointegration Tests

\begin{tabular}{|c|c|c|c|c|}
\hline & lt & lv & ee & $\mathrm{cZ}$ \\
\hline Note & 20.5383 & 34.5469 & 23.4548 & 35.4818 \\
\hline At most 1 & 0.13187 & 0.89765 & 0.1613 & 0.90621 \\
\hline Reject: $\mathrm{H}_{0}$ None & $1 \%$ & $1 \%$ & $1 \%$ & $1 \%$ \\
\hline Reject: $\mathrm{H}_{0}$ AT1 & N.R. & N.R. & N.R. & N.R. \\
\hline \multirow[t]{2}{*}{ N. coint. rel.s } & 1 & 1 & 1 & 1 \\
\hline & sk & $\mathrm{pl}$ & $\mathrm{sl}$ & hu \\
\hline Note & 22.1195 & 19.2495 & 34.939 & 33.1737 \\
\hline At most 1 & 0.28573 & 0.13980 & 0.01077 & 0.23426 \\
\hline Reject: $\mathrm{H}_{0}$ None & $1 \%$ & $1 \%$ & $1 \%$ & $1 \%$ \\
\hline Reject: $\mathrm{H}_{0}$ AT1 & N.R. & N.R. & N.R. & N.R. \\
\hline \multirow[t]{2}{*}{ N. coint. rel.s } & 1 & 1 & 1 & 1 \\
\hline & Critical Values & $5 \%$ & $1 \%$ & \\
\hline \multirow[t]{2}{*}{ None } & & 12.53 & 16.31 & \\
\hline & AT1 & 3.84 & 6.51 & \\
\hline
\end{tabular}

Source: Eurostat (2007) National Accounts, own calculations. $(T=48)$. Note: N.R. not rejected. 
specification is not enough to capture the asymmetries and time-varying adjustments in some countries (especially Slovakia and the Czech Republic).

Secondly Carlino and Mills (1993) relaxed the strength of the time-series convergence hypothesis introducing the concept of trend stationarity paired with positive beta-convergence. An alternative generalization is to see the problem in terms of stochastic unit roots instead of fixed unit root, maintaining the link with beta convergence at the same time. This would introduce a definition of stochastic convergence related to stochastic unit roots.

Finally, there is positive evidence in the literature that a great number of existing studies - almost half according to Leybourne et al. (1996) - failed to reject the null of a unit root mainly because of an inappropriate linear specification.

Following Granger and Swanson (1997), we reformulate the unit-root problem in Section IV.A starting from the STUR process:

$$
g_{t}=a_{t} g_{t-1}+\varepsilon_{t}
$$

where $a_{t}$ is now a stationary series such as $a_{t} \sim \operatorname{iid}\left(1, w^{2}\right)$ and $\varepsilon_{t} \sim \operatorname{iid}\left(0, \sigma^{2}\right)$. When $a_{t}=1, \forall t$ the STUR exhibits a pure unit-root ( $a_{t}$ collapsing to $\rho=1$, $\alpha=0$ ). Whilst the existence of a pure unit-root is usually tested through standard or augmented Dickey and Fuller (1979) test as in section IV.A, for the stochastic variant Leybourne et al. (1996) developed an ad-hoc LM test and simulated the following test statistic based on (7), augmented for $q$ lags :

$$
\hat{Z}_{T}=\frac{\sum_{t=q+3}^{T}\left[\left(\sum_{p=q+2}^{t-1} \hat{\varepsilon}_{p}\right)^{2}\left(\hat{\varepsilon}_{t}-\hat{\sigma}^{2}\right)\right]}{\hat{k} \hat{\sigma}^{2} \sqrt{T^{3}}}
$$

assuming the residual component is estimated as:

and:

$$
\hat{\varepsilon}_{t}=\Delta x_{t}-\hat{\alpha}-\hat{\gamma} t-\sum_{n=1}^{q} \hat{\beta}_{n} \Delta x_{t-n}
$$

$$
\hat{\sigma}^{2}=T^{-1} \sum_{t=1}^{T} \hat{\varepsilon}_{t}^{2}, k^{2}=T^{-1} \sum_{t=1}^{T}\left(\hat{\varepsilon}_{t}-\hat{\sigma}^{2}\right) .
$$

The null hypothesis is set to the pure unit-root ${ }^{15}$

$$
\mathrm{H}_{0}: w^{2}=0, \mathrm{H}_{1}: w^{2}>0
$$

against a more general STUR process. Granger and Swanson (1997) suggest the opposite would be more effective but the cost is a far more complex simulation of 
the test statistic, which is understandably avoided by Leybourne et al. (1996).

The procedure we use here is similar to Yau and Hung (2007) but applied to the EU enlargement case. When the null is rejected in favour of a stochastic unit root (STUR), the GDP per capita of the individual new member converges to the EU15 aggregate. The table below 5 illustrates our results.

More generally, a log difference GDP per capita of two countries starting at different levels showing a STUR, is interpreted as a signal of for converge. Taking into account potential non-linear dynamics seems to suggest positive evidence of convergence between EE, SL, HU and EU15. Moreover we are able to confirm beta convergence in the countries where we reject the null of a pure unit-root. For these, we can conclude, similarly to Carlino and Mills (1993), for stochastic convergence.

\section{Structural Changes and Asymmetric Adjustments}

Since Perron (1989) it is clear that performing a unit-root test in the presence of a structural change can lead to non-rejection of the null when in fact it is not true. This section explores a set of potential solutions to the problem.

The existing literature on structural breaks offers a wide range of choices, among those we are looking for the possibility of allowing an unknown break date. Traditionally the Zivot and Andrews (1992), Perron (1997) tests are used under this circumstances or the iterative equivalent of Chow (1960) proposed by Andrews (1993) and Andrews and Ploberger (1994) and their extensions to the multi-break scenario (see Bai and Perron, 1998 or Bai and Perron, 2003 etc.). In the convergence literature, the Lee and Strazicich (2003) two-breaks LM test has been used by Bruggemann and Trenkler (2007) and Cunado and Perez de Garcia (2006)

Table 5. Leybourne Tests for a Stochastic Unit Root

\begin{tabular}{ccccc}
\hline & lt & lv & ee & cz \\
\hline Z-stat & -0.021092 & 0.025811 & $0.224499^{*}$ & 0.011203 \\
STUR? & no & no & yes & no \\
\hline Z-stat & sk & pl & sl & hu \\
\hline STUR? & 0.113485 & 0.011203 & $0.25118^{*}$ & 0.287285 \\
\hline
\end{tabular}

Source: Eurostat (2007) National Accounts, own calculations. ( $(\mathrm{T}=48)$. Note: Leybourne et al. (1996), 5\% critical values: 0.215 .

$\overline{{ }^{15} \text { When } w^{2}=0, \alpha_{t} \sim \operatorname{iid}(0,1)}$ is equivalent to $\rho=1$ i.e. a non stationary random walk in the model (7). 
on a selected group of new member states.

Recently Christopoulos and Leon-Ledesma (2007) proposed a three steps procedure to test for a unit root in presence of multiple "smooth" unknown breaks. These are modelled in the form of a Fourier expansion according to:

$$
y_{t}=\delta_{0}+\delta_{1} \sin \left(\frac{2 \pi k t}{T}\right)+\delta_{2} \cos \left(\frac{2 \pi k t}{T}\right)+v_{t}
$$

where $k$ is an estimated constant used to control the number of frequencies of the trigonometric function.

A preliminary stationarity test is performed on estimated residuals from (8):

$$
\Delta \hat{v}_{t}=\alpha v_{t-1}+\Sigma_{j=1}^{p} \beta_{j} \Delta \hat{v}_{t-j}+u_{t}
$$

setting the null hypothesis to $\mathrm{H}_{0}: \alpha=0, \mathrm{H}_{1}: \alpha \neq 0$ and simulating the limiting distribution of the test (labelled as FADF) with reference to the standard t-statistic .

The authors also suggest to model the residual (9) as a non-linear LTAR process and use the appropriate inf- $t_{L T A R}$ statistic proposed by Park and Shintani (2005) to test for a unit-root. Although we see the opportunity of using a logistic transition function to measure the speed of mean reversion in relation to the current distance from steady state, ${ }^{16}$ we also acknowledge the contribution of Choi and Moh (2007). In a comprehensive assessment of the power properties of 16 nonlinear tests for unit-roots - including Park and Shintani (2005) inf- $t_{L T A R}-$ they conclude that in small samples $(\mathrm{T}=50)$ the ADF test is comparable or outperforms all its competitors regardless of the true data generating process. We take this consideration as an indication not to expect significantly different conclusions on the existence of a unit-root, assuming a linear behaviour when the residuals are in

Table 6. Estimated $k-$ SSRs.

\begin{tabular}{ccccccccc}
\hline$k \backslash$ Country & cz & ee & hu & lt & lv & pl & sk & sl \\
\hline 1 & $0.04^{*}$ & $0.93^{*}$ & $0.15^{*}$ & $0.65^{*}$ & $0.85^{*}$ & $0.18^{*}$ & $0.19^{*}$ & $0.12^{*}$ \\
2 & 0.12 & 1.83 & 0.36 & 1.15 & 1.68 & 0.23 & 0.23 & 0.19 \\
3 & 0.12 & 1.91 & 0.40 & 1.28 & 1.79 & 0.28 & 0.25 & 0.22 \\
4 & 0.12 & 2.04 & 0.42 & 1.37 & 1.89 & 0.29 & 0.27 & 0.23 \\
5 & 0.12 & 2.11 & 0.42 & 1.37 & 1.93 & 0.29 & 0.27 & 0.23 \\
\hline
\end{tabular}

Note: $*$ indicates minimum SSR

\footnotetext{
${ }^{16}$ See Section IV.B.
} 
fact non-linear.

If the disturbances are found to be stationary ${ }^{17}$ Christopoulos and Leon-Ledesma (2007) suggest to apply the F-statistic proposed by Becker et al. (2006) to test the presence of an unknown break. This conclusion is achieved imposing the trigonometric term in (8) equal to zero under the null. The break is set to the alternative hypothesis i.e.:

$$
\mathrm{H}_{0}: \delta_{1}=\delta_{2}=0, \mathrm{H}_{1}: \delta_{1} \neq 0 \cup \delta_{2} \neq 0
$$

The introduction of a trigonometric trend has the further advantage of correcting for potential cyclical components in the data. Since we are using higher frequencies in the time-series in comparison to beta-convergence, Christopoulos and LeonLedesma (2007) is particularly appealing to us.

The frequency $k$ is estimated in the range $k=1,2, \ldots \ldots, 5$ with reference to model (8) and the value returning the lower SSR is chosen: $k=\arg \underset{k \in[1,5]}{\min }\left(S S R_{k}\right)$ with $S S R_{k}=\sum_{i=2}^{T}\left(v_{i}^{2}\right)$. Not surprisingly the optimal frequency in the given set proved to be the unity (see Table 6).

The FADF statistic calculated on the residuals $u_{t}$ for $k=1$ and $y_{t}=g_{t}$ is reported in Table 7 whilst the Fourier series and the estimated disturbances are plotted in Figure A2 in the Appendix.

The clear result is that all the $v_{t}$ series for every country under investigation are non-stationary and following Choi and Moh (2007) we extend this conclusion to the inf- $t$ test. This not entirely surprisingly giving the dynamics of the series plotted in Figure A2. We interpret the non-stationary residuals as evidence of no breaks in our series for the given sample and we note they tend to be stationary around a

Table 7. FADF Tests

\begin{tabular}{ccccc}
\hline Country & $k$ & FADF & $p$ & Reject $\mathrm{H}_{0} ?$ \\
\hline ee & 1 & -1.08 & 3 & no \\
lv & 1 & -1.38 & 4 & no \\
lt & 1 & -0.23 & 6 & no \\
hu & 1 & -1.23 & 4 & no \\
pl & 1 & -0.37 & 4 & no \\
sl & 1 & -0.92 & 0 & no \\
cz & 1 & -1.73 & 0 & no \\
sk & 1 & -0.39 & 4 & no \\
\hline
\end{tabular}

Notes: Leon-Ledesma et al. (2007) 5\% critical value: -3.92. $p$ : number of lags (SIC).

${ }^{17}$ If the opposite is true, Becker et al. (2006) has low power and should be avoided. 
(negative) linear trend as far as $k \rightarrow 0$ and $k<1$. In the impossibility of running a reliable $F$-test, we interpret this behaviour as an alternative to Becker et al. (2006). The lesson we learned from our results is that the Christopoulos and LeonLedesma (2007) procedure has better performance in large samples with low frequency data rather than small samples and higher frequencies where seasonalities are removed a priori. We also use this finding as evidence against the presence of cyclical components in our data.

\section{Comparison}

Table 8 summarises the results of the previous sections. In particular, it is interesting to analyse the role of the STUR in our empirical exercise. A problem of the standard ADF tests is to assume linearisation around the steady state, which results in a constant speed of mean reversion. However it is a consequence of Barro and Sala-i-Martin (1992) that the speed of convergence depends on the distance from steady state and it is not necessarily fixed. In particular, assuming a group of transition economy shared the same steady states with a group of developed countries can be too restrictive. Christopoulos and Leon-Ledesma (2007) allow for an asymmetric speed of adjustment using a LTAR model applied to the estimated residuals from a Fourier series.

As explained above, we found that the procedure is not very effective in our particular case and argue that it might be a general problem arising from working in small samples. In order to partially offset these difficulties, we imposed a nonlinear variant of the linear ADF test which is independent on the existence of breaks with some improvements on our initial results. Although this approach does not give any indication on the speed of convergence per se it allows for some deviations around the steady state.

A subjective judgment on convergence is attempted on the basis of the empirical results obtained through the various tests applied to the Eurostat dataset. Where possible the level of reliability of the conclusion is provided as an indication for the

Table 8. Time-series Convergence?

\begin{tabular}{ccccccccc}
\hline & hu & sl & ee & lv & lt & sk & pl & cz \\
\hline ADF & Y & N & N & N & N & N & Y+ & N \\
STUR & Y & Y & Y & N & N & N & N & N \\
Cointegration & Y & Y & Y & Y & Y & Y & Y & Y \\
Overall & Y & Y- & Y- & N & N & N & Y & N \\
\hline
\end{tabular}

Note: $\mathrm{Y}$ (yes) is positive evidence of convergence. $\mathrm{N}$ (no) is no evidence of convergence. 
reader.

Quite differently from the aggregated beta-convergence analysis, we can now see some degree of heterogeneity among the EU8 countries. The new results could potentially be explained by the different theoretical foundation under the new methodology, although differences among countries do not necessarily exclude an aggregate behaviour like the one observed in Section III.A. The econometric difficulties underlined in this section may also contribute to a less clear answer.

\section{Conclusions}

Some authors claim one of the main determinants of convergence is a process of economic integration associated with the elimination of trade barriers, factors movements, technology transfers etc. All these influences should stimulate growth and give rise to narrow income disparities. However this is not a view fully supported by the literature: new theories of economic growth warn that integration could lead to the very opposite outcome - see e.g. Matkowski and Prochniak (2004). Our empirical results reflect both sides of the debate. Beta analysis suggests that overall there is a relatively strong convergence which is not confirm by sigma between groups of countries (EU8 and EU15). Especially in the last few years EU8 countries made rapid progress both in narrowing gap and reducing income divergence within the group but not necessarily against the EU15. Moreover, giving credit to Bernard and Durlaf (1995) and Quah (1993) and looking at country-specific dynamics, introduces the need of adopting a broader concept of convergence leading to a less defined picture for the enlarged Europe. This research should prove in a very peculiar setting that, regardless its determinants it is difficult to find a strong empirical argument in support or against integration-lead convergence. We observed some signs of this process taking place in the eight new members of the EU and we provided an indication of their magnitude but we have no strong evidence to conclude in one sense or the other. What seems to be reality under one perspective, is very close to a myth under the other.

\section{Acknowledgements}

Part of the work was written with the support of grants provided by the Czech Grant Agency (Growth performance and qualitative competitiveness of the Czech economy 402/05/2210) and by the Ministry of Education, Youth and Sports 
(Centre for research of the Czech economy's competitiveness 1M0524). The authors wish also to acknowledge the valuable feedback and contributions of Vincent Daly, Willy Spanjiers, two anonymous referees and participants at the 6th EEFS Annual conference, University of the National and World Economy, Sofia, May 31st - June 3rd 2007. All remaining mistakes are ours.

Part of the work was written with the support of grants provided by the Czech Grant Agency (Growth performance and qualitative competitiveness of the Czech economy 402/05/2210) and by the Ministry of Education, Youth and Sports (Centre for research of the Czech economy's competitiveness 1M0524). The authors wish also to acknowledge the valuable feedback and contributions of Vincent Daly, Willy Spanjiers, two anonymous referees and participants at the 6th EEFS Annual conference, University of the National and World Economy, Sofia, May 31st - June 3rd 2007. All remaining mistakes are ours.

Received 25 October 2007, Revised 30 June 2008, Accepted 16 October 2008 


\section{Appendix}

Figure A1. GDP per capita Dynamics - EU8 (Euros and PPS).
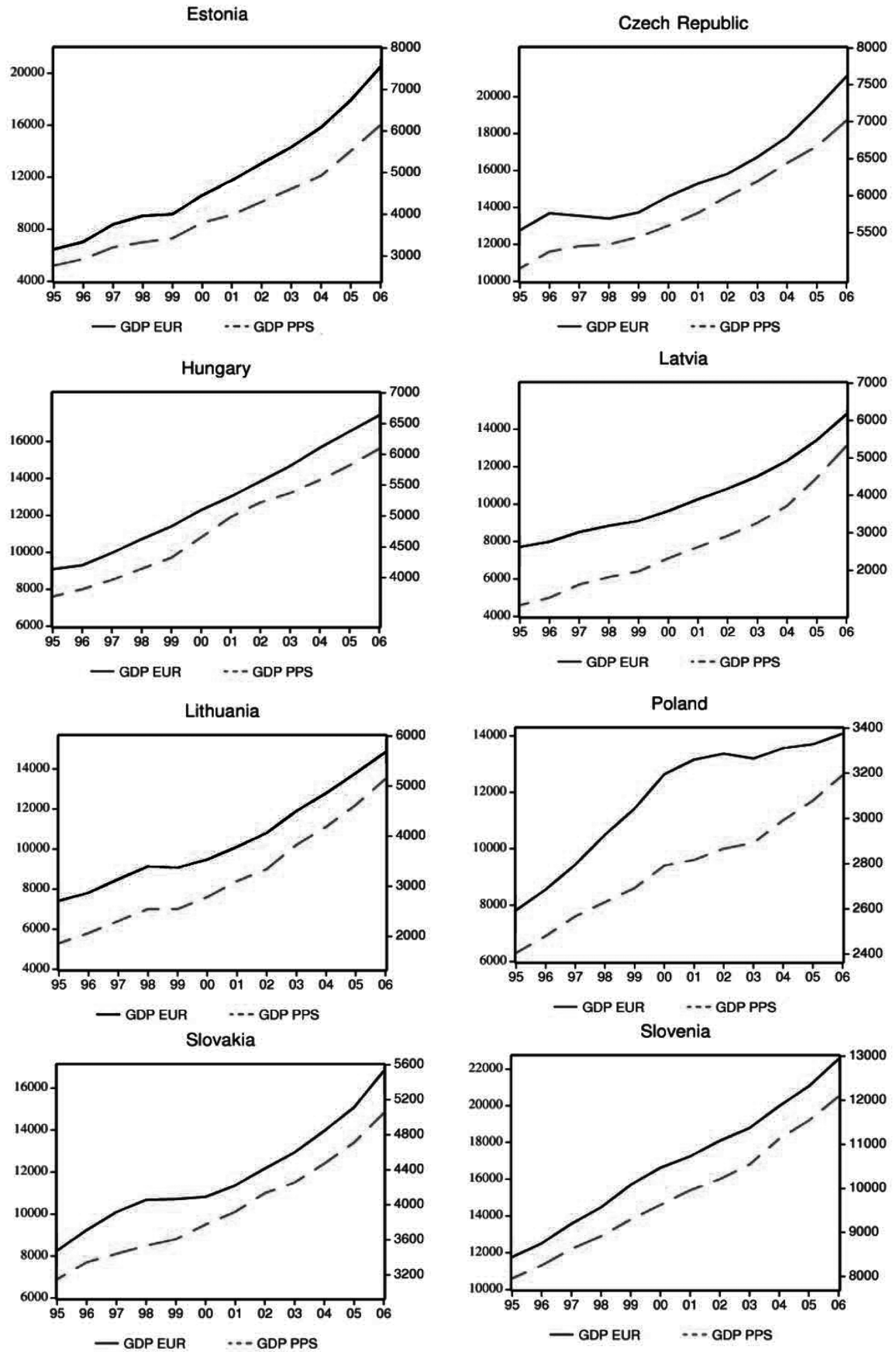
Figure A2. Fourier Series and Estimated Residuals

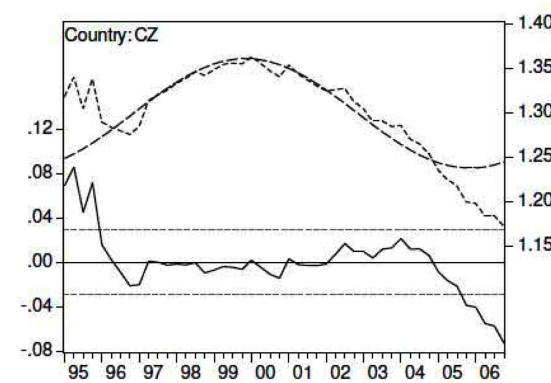

- Residual ----- Actual --- Fitted

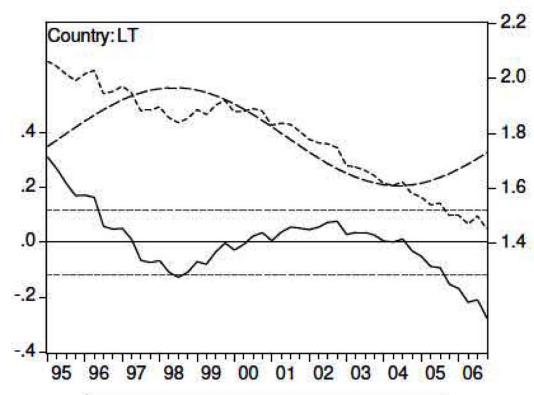

- Residual ----- Actual --- Fitted

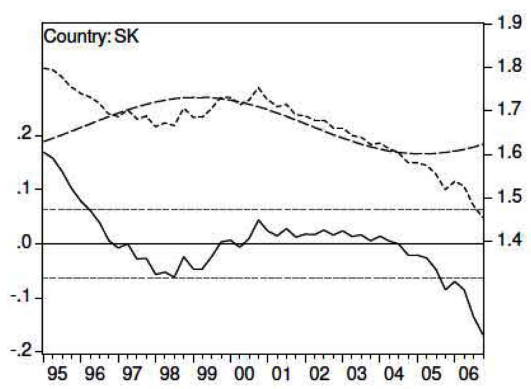

- Residual ----- Actual --- Fitted

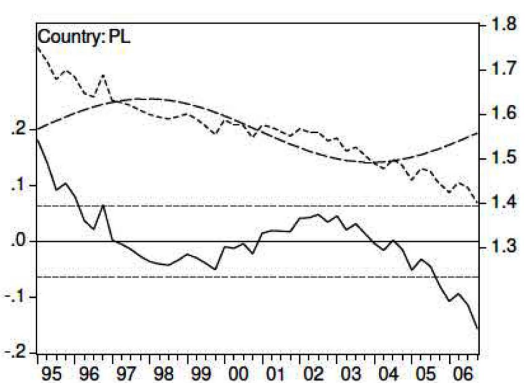

- Residual ----- Actual --- Fitted

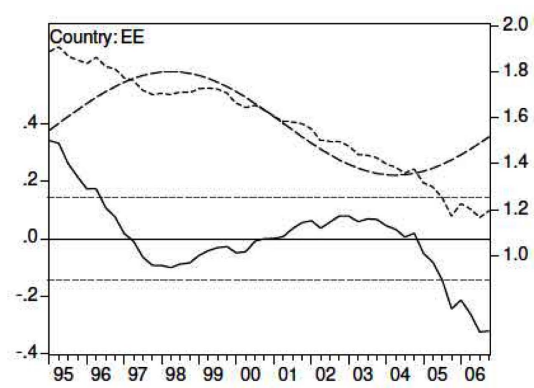

- Residual ----- Actual --- Fitted
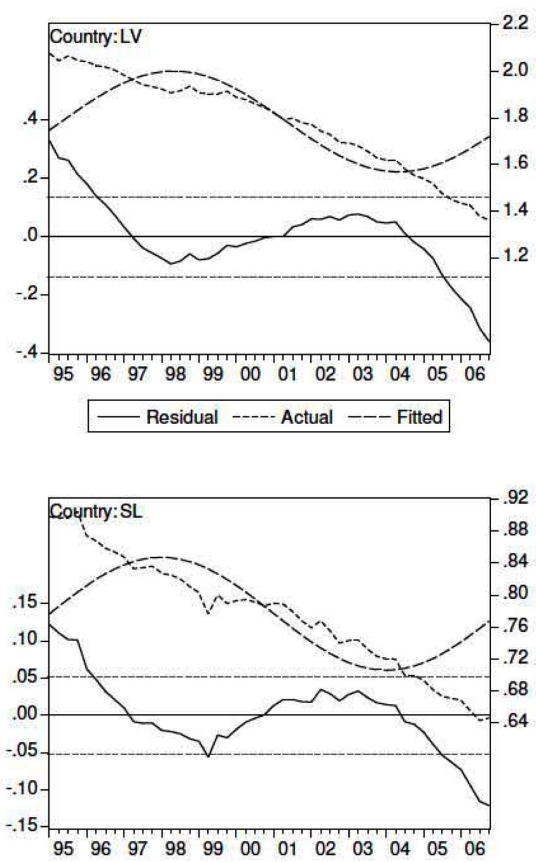

- Residual ----- Actual --- Fitted

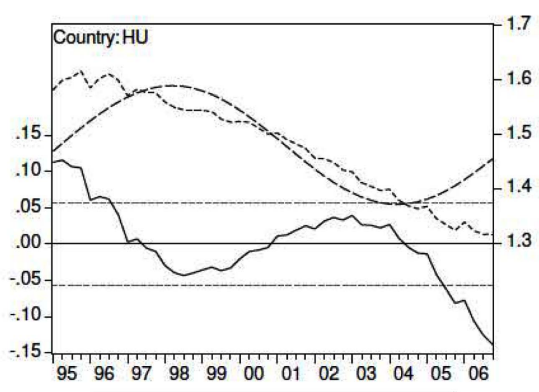

- Residual ---- Actual --- Fitted 


\section{References}

Andrews, D. W. K. (1993), "Tests for Parameter Instability and Structural Change with Unknown Change Point”, Econometrica, 61 (4), pp. 821-56.

Andrews, D. W. K., Ploberger, W. (1994), "Optimal Tests When a Nuisance Parameter Is Present Only under the Alternative", Econometrica, 62 (6), pp. 1383-1414.

Bai, J., Perron, P. (1998), "Estimating and Testing Linear Models with Multiple Structural Changes", Econometrica, 66 (1), pp. 47-78.

Bai, J., Perron, P. (2003), "Computation and Analysis of Multiple Structural Change Models", Journal of Applied Econometrics, 18 (1), pp. 1-22.

Barro, R. J., Sala-Martin, X. (1992), “Convergence”, Journal of political economy, 100 (2), pp. 223-251.

Becker, R., Enders, W., Lee, J. (2006), “A stationarity Test in the Presence of an Unknown Number of Smooth Breaks", Journal of Time Series Analysis, 27 (3), pp. 381-409.

Bernard, A. B., Durlaf, S. N. (1995), "Convergence in International Output", Journal of Applied Econometrics, 10 (2), pp. 97-108.

Bernard, A. B., Durlauf, S. N. (1996), "Interpreting Tests of the Convergence Hypothesis", Journal of Econometrics, 71 (1), pp. 161-173.

Bonn, U.,Welsch, H (2006), "Is There a Real Divergence in the European Union? A Comment", Structural Change and Economics Dynamics, 17 (2), pp. 259-265.

Bruggemann, R., Trenkler, C. (2004), "Real Convergence in Eastern European Countries: Time Series Evidence for Czech Republic", Hungary and Poland, Available at http:/ /www.iue.it/ECO/Conferences/accession countries/papers/EUIconferenceMay2004 paperBruggeman.pdf.

Bruggemann, R., Trenkler, C. (2007), “Are Eastern European countries catching up? Time Series Evidence for Czech Republic, Hungary, and Poland", Applied Economics Letters, 14 (4-6), pp. 245-249.

Carlino, G. A., Mills, L. O. (1993), "Are U.S. Regional Incomes Converging? A time Series Analysis", Journal of Monetary Economics, 32 (2), pp. 335-346.

Cass, D. M. (1965), "Optimum Growth in an Aggregate Model of Capital Accumulation", Review of Economic Studies, 32 (3), pp. 233-240.

Choi, C. Y., Moh, Y. K. (2007), "How useful are Tests for Unit-root in Distinguishing Unit Root Processes from Stationary but Non-linear Processes", The Econometrics Journal, 10 (1), pp. 82-112(31).

Chow, G. C. (1960), "Tests of Equality between Sets of Coefficients in Two Linear Regressions", Econometrica, 28 (3), pp. 591-605.

Christopoulos, D. K., Leon-Ledesma, M. A. (2007), "International Output Convergence, Breaks, and Asymmetric Adjustment", Available at http://home.ceders.org/m.martelli/ International Output Convergence, Breaks and Asymmetric Adjustment.pdf.

Cunado, J., Perez de Garcia, F. (2006), "Real Convergence in Some Central and Eastern European Countries", Applied Economics, 38 (20), pp. 2433-2441. 
Daly, V., Li, H. (2005), "Convergence of Chinese Regional and Provincial Economic Performance: an Empirical Investigation”, International Journal of Development Issues, 4 (1), pp. 49-70.

Dickey, D., Fuller, W. (1979), "Distribution of the Estimators for Autoregressive Time Series with a Unit Root", Journal of the American Statistical Association, Vol. 74, pp. 427-431.

Dobozi, I., Pohl, G. (1995), "Real Output Decline in Transition Economies?", Transition, 6 (1-2), pp. 17-18.

Dobrinsky, R. (2003), "Convergence in Per Capita Income Levels, Productivity Dynamics and Real Exchange Rates in the Eu Acceding Countries", Empirica, 30 (3), pp. 305 334.

Dobrinsky, R., Hesse, D., Traeger, R. (2006), "Understanding the Long-term Growth Performance of the East European and CIS Economies", ECE Discussion Papers Series 1 , UNECE.

ECFIN (2006), "Statistical Annex to the European Economy", Technical Report Autumn, Directorate General Economic Commission Finance.

Engle, R. F., Granger, C. W. J. (1987), "Co-integration and Error Correction: Representation, Estimation, and Testing", Econometrica, 55 (2), pp. 251-276.

Filer, R. K., Hanousek, J. (2004), "Consumers' opinion of inflation bias due to quality improvements", William Davidson Institute Working Paper, (681).

Granger, C. W. J., Swanson, N. R. (1997), “An introduction to Stochastic Unit-root Processes”, Journal of Econometrics, 80 (1), pp. 35-62.

IMF (2007), "World Economic Outlook, Globalization and Inequality", Technical Report, IMF, Washington D.C. October.

Johansen, S. (1991), "Estimation and Hypothesis testing of Cointegration Vectors in Gaussian Vector Autoregressive Models", Econometrica, 59 (6), pp. 1551-1580.

Johansen, S. (1995), "A statistical Analysis of Cointegration for I(2) Variables", Econometric Theory, 11 (1), pp. 25-59.

Johansen, S. (2002), "A small Sample Correction for the Test of Cointegrating Rank in the Vector Autoregressive Model”, Econometrica, 70 (5), pp. 1929-1961.

Kocenda, E. (2001), "Macroeconomic Convergence in Transition Countries", Journal of Comparative Economics, 29 (1), pp. 1-23.

Kocenda, E., Kutan, A., Yigit, T. (2006), "Pilgrims to the Eurozone: How Far, How Fast?", Economic Systems, 30 (4), pp. 311-327.

Kutan, A. M., Yigit, T. M. (2004), "Nominal and Real Stochastic Convergence of Transition Economies", Journal of Comparative Economics, 32 (1), pp. 23-36.

Kutan, A. M., Yigit, T. M. (2007), "European Integration, Productivity Growth and Real Convergence", European Economic Review, 51 (6), pp. 1370-1395.

Lee, J., Strazicich, M. C. (2003), "Minimum Lagrange Multiplier Unit Root Test with Two Structural Breaks", The Review Of Economics And Statistics, 85 (4), pp. 10821089.

Leybourne, S. J., McCabe, B. P. M., Tremayne, A. R. (1996), “Can Economic Time Series 
be Differenced to Stationarity?", Journal of Business and Economic Statistics, 14 (4), pp. 435-446.

Matkowski, Z., Prochniak, M. (2004), "Real Economic Convergence in the EU Accession countries", International Journal of Applied Econometrics and Quantitative Studies, 1 (3).

Matkowski, Z., Próchniak, M. (2007a), "Economic Convergence between the CEE-8 and the European Union", Eastern European Economics, 45 (1), pp. 59-76.

Matkowski, Z., Próchniak, M. (2007b), "Real Convergence or Divergence of the Average Level of GDP Per Capita", in Weresa, M. A., ed., Poland Competitiveness Report 2007, The Role of Foreign Direct Investment, pp. 35-45. Warsaw.

Osterwald-Lenum, M. (1992), "A Note with Quantiles of the Asymptotic Distribution of the Maximum Likelihood Cointegration Rank Test Statistics", Oxford Bulletin of Economics and Statistics, 54 (3), pp. 461-472.

Park, J. Y., Shintani, M. (2005), "Testing for a Unit Root Against Transitional Autoregressive Models", Working Papers 05010, Department of Economics, Vanderbilt University.

Perron, P. (1989), "The Great Crash, the Oil Price Shock and the Unit Root Hypothesis", Econometrica, 57 (6), pp. 1361-1401.

Perron, P. (1997), "Further Evidence on Breaking Trend Functions in Macroeconomic Variables", Journal of Econometrics, 80 (2), pp. 355-385.

Quah, D. (1993), "Galton's Fallacy and Tests of the Convergence Hypothesis", Technical Report 820, C.E.P.R. Discussion Papers.

Solow, R. M. (1956), "A Contribution to the Theory of Economic Growth”, Quarterly Journal of Economics, 70 (1), pp. 65-94.

UNECE (2000), "Economic Survey of Europe", Technical Report 1, United Nations Economic Commission for Europe.

Yau, R., Hung, C. J. (2007), "Output Convergence Revisited: New Time Series Results on Industrialized Countries", Applied Economic Letters, 14 (1), pp. 75-77.

Young, A., Higgins, M., Levy, D. (2008), "Sigma Convergence Versus Beta Convergence: Evidence from U.S. County-Level Data", Journal of Money Credit and Banking, 40 (5), pp. 1083-1093.

Zivot, E., Andrews, D. W. K. (1992), "Further Evidence on the Great Crash, the Oil Price Shock and the Unit Root Hypothesis", Journal of Business and Economic Statistics, 10 (3), pp. 251-270. 